\title{
A Study of the Flow Field Surrounding Interacting Line Fires
}

\author{
Trevor Maynard, ${ }^{1}$ Marko Princevac, ${ }^{2}$ and David R. Weise ${ }^{3}$ \\ ${ }^{1}$ Bureau of Alcohol, Tobacco, Firearms and Explosives, Fire Research Laboratory, Beltsville, MD 20705, USA \\ ${ }^{2}$ Department of Mechanical Engineering, Bourns College of Engineering, University of California, Riverside, Riverside, CA 92521, USA \\ ${ }^{3}$ USDA Forest Service, Pacific Southwest Research Station, Forest Fire Laboratory, Riverside, CA 92507, USA
}

Correspondence should be addressed to Trevor Maynard; trevor.maynard@atf.gov

Received 31 August 2016; Revised 21 October 2016; Accepted 24 November 2016

Academic Editor: Michael A. Delichatsios

Copyright (C) 2016 Trevor Maynard et al. This is an open access article distributed under the Creative Commons Attribution License, which permits unrestricted use, distribution, and reproduction in any medium, provided the original work is properly cited.

\begin{abstract}
The interaction of converging fires often leads to significant changes in fire behavior, including increased flame length, angle, and intensity. In this paper, the fluid mechanics of two adjacent line fires are studied both theoretically and experimentally. A simple potential flow model is used to explain the tilting of interacting flames towards each other, which results from a momentum imbalance triggered by fire geometry. The model was validated by measuring the velocity field surrounding stationary alcohol pool fires. The flow field was seeded with high-contrast colored smoke, and the motion of smoke structures was analyzed using a crosscorrelation optical flow technique. The measured velocities and flame angles are found to compare reasonably with the predicted values, and an analogy between merging fires and wind-blown flames is proposed.
\end{abstract}

\section{Introduction}

As two or more freely burning fires converge, their behavior can change, sometimes significantly (Figure 1). Flame length, flame angle, heat release rate, and propagation rate (for spreading fires) have all been observed to increase during flame merging $[1,2]$. Aside from being an intriguing physical problem, fire interactions can prove challenging for firefighters, who are often required to adjust tactics to maintain control of the fire. Fire interactions are used frequently to control intensity of prescribed vegetation fires in order to achieve natural resource management objectives [3-5].

Flame interactions are common in both vegetation and structure fires. During wildland fires, interactions may occur naturally or may be induced to produce desired behavior (Figure 2). Increased flame length and fire intensity can be especially problematic in prescribed (controlled) vegetation fires, as this can lead to undesired tree and plant mortality [1]. In addition, the ability of a wildland fire to propel embers over long distances (which can serve as new ignition sources) is directly related to its intensity [6]. Flame interactions are also prevalent in urban area fires. Countryman [7] cites numerous conflagrations in the early 20th century, including the bombings of Dresden and Hamburg, Germany, during World War
II, as prime examples of destructive fire behavior. These cities were principally damaged not by the bombs themselves but by the resulting groups of fires ("mass fires"), which induced extreme winds and burning rates.

The physical interaction of two flames is a complex process which has been examined both theoretically and with numerical physical models [8]. Liu et al. [9] showed that the burning rate of pool fire arrays increased as their separation distance decreased. This effect occurred until a critical separation was reached, below which the burning rate began to decrease. They explained the initial rise in combustion rate as a result of an increased radiation view factor (enhancement of heat feedback to burning fuels), while the eventual decline was due to restriction of airflow into each fire. For spreading fires, as flames converge, the radiant energy emitted by each flame heats the intervening fuels, leading to accelerated fire spread [10]. More recently, Lu et al. [11] studied the merging behaviors of flames ejected from neighboring windows in reduced-scale compartment fires at constant rates of heat release. As distance between windows decreased, the individual flames eventually merged into a single flame. They observed three regimes of merging: continuous, intermittent, and unmerged. Intermittent merging began at a separation distance of $D / Z<0.3$, where $D$ is the separation distance and 

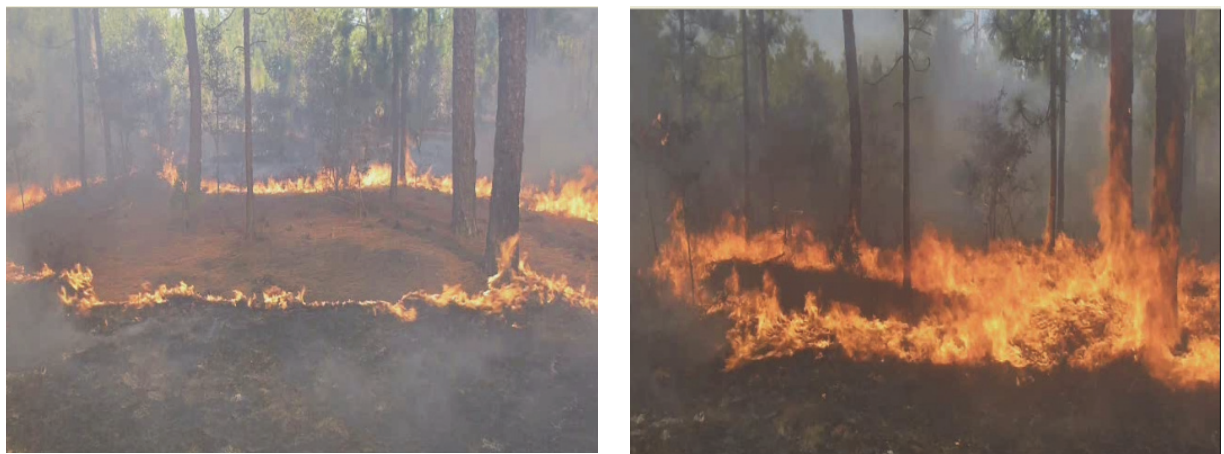

FIGURE 1: Merging of a ring of fire burning in longleaf pine understory (Pinus palustris Mill). Note the significant change in fire behavior as the flame fronts converge.

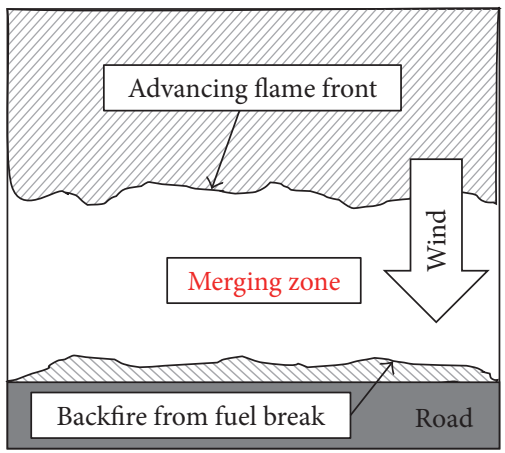

(a)

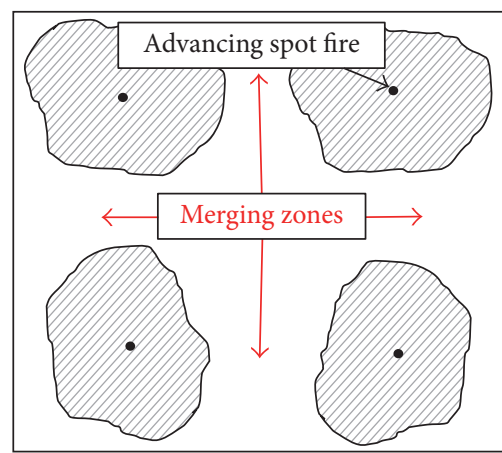

(b)

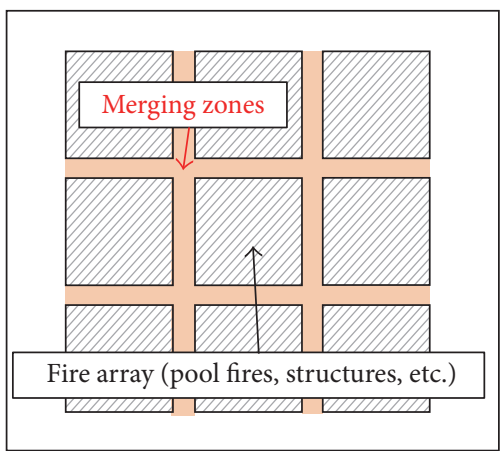

(c)

Figure 2: Example scenarios for fire interactions: (a) backfiring from a fuel break to stop an advancing wildfire, (b) merging of individual vegetation fires, and (c) interaction of multiple burning objects (structures, pool fires, etc.).

$Z$ is the unmerged flame height. Flames were continuously merged for $D / Z<0.1$. The probability of merging was primarily a function of window separation, but window dimension also had an effect. Kuwana et al. [12] studied the behavior of two adjacent microscale slot flames and noted that the overall heat release increased as burner space decreased, but both flames eventually merged into a unified flame.

While much of the work on merging fires has focused on radiant heat transfer, entrainment and convection also appear to play a significant role in interactions. As two flames converge, their independent entrainment fields interact, resulting in an inward tilting of the flames $[13,14]$. Flame tilt affects fire behavior by increasing the amount of radiant heat transfer (view factor) to the surface [15] by increasing the horizontal component of convective heat flux forward of the flame [16]. Baldwin et al. [17] theorized that flame tilt is a product of the flow restriction between flames, which causes a pressure drop that competes with buoyancy. A similar mechanism has also been proposed for noncombusting buoyant plumes at laboratory scale [18]. Recent work on wind-blown flames (though not interacting) has provided additional insight into the mechanisms of flame tilt. Jiang and $\mathrm{Lu}$ [19] measured the burning rate and flame angle of wind-blown pool fires and demonstrated that flame tilt was a function of Froude number (Fr). Flame tilt initially increased rapidly in the range of $0<$ Fr $<1$, but quickly moderated for $\mathrm{Fr}>2$. Hu et al. [20] correlated flame tilt angle against the ratio of cross-flow speed to the characteristic buoyant velocity of heptane pool fires, and these results were recently extended to optically thin heptane fires in cross-flow [21]. Tang et al. [22] demonstrated that, for small pool fires, flame tilt was more easily influenced by wind speed as opposed to larger fires. Similar studies have been done for pool fires in momentum-dominated regimes $[23,24]$ and flame angle was shown to be a function of the cross-flow to burner vertical momentum ratio. Tang et al. [25] studied the behavior of wind-blown gas burner flames in the presence of walls (walls parallel to cross-flow), which are potentially analogous to merging flames (entrainment restricted). Interestingly, as the flame was moved closer to the wall, for the same cross-flow speed, flame tilt decreased. Their observations of rate of flame angle change with crossflow speed were similar to that of Jiang and $\mathrm{Lu}$ [19]. Tang et al. [26] performed experiments with rectangular pool fires of varying aspect ratio and demonstrated that flame angle increased with cross-flow velocity, but aspect ratio did not have a major impact.

Flame length for interacting fires has also been studied. For gas burners with constant heat release rate, Wan et al. [27] demonstrated that the dependency of flame length on fire spacing was coupled with heat release rate. For smaller heat release rates, flame length was largely unchanged as spacing between fires decreased, while it was affected at higher rates of heat release. They also observed that merging occurred when flames were at a spacing of less than 30 percent of the single 
flame height. Lu et al. [11] also demonstrated that the height of merging façade flames increased as separation distance decreased. For noninteracting pool fires in cross-flows, flame length has been shown to increase linearly with the Froude number based on wind speed [22]. For buoyant line-source jet flames in cross-flows, Zhang et al. [24] showed that vertical flame height correlated with the ratio of fuel jet to cross-flow momentum to the $2 / 5$ power, and flame length (horizontal) correlated with the product of the momentum ratio and Fr to the $1 / 3$ power.

For line fires, Baldwin et al. [17] used Bernoulli's equation, combined with the entrainment assumption, to develop a model for flame length and angle as a function of separation distance, line length, and flame zone depth (width of flame). However, as discussed by Smith et al. [28], classical plume models which assume that entrainment is due only to the turbulent diffusion of momentum as the plume expands [29] are not completely appropriate for characterizing the induction of air into large fires. Unlike isothermal buoyant plumes, the combustion process releases a tremendous amount of heat and requires significant amounts of oxygen for sustenance. Turbulent entrainment alone cannot provide a sufficient volume of air, leading to the existence of a horizontal inflow over the fire perimeter, called the fire wind. They note that this is far-field entrainment, where the dynamic pressure field is the medium which communicates the effect of buoyancy to the surrounding fluid.

In this paper, we develop a simple model to describe the tilting and interaction of adjacent flames. The model uses the conservation of linear momentum, coupled with potential flow theory, to describe the behavior of the flow field surrounding two fires as a function of separation distance. The model is compared with experiments to determine the velocity field outside of adjacent alcohol pool fires using cross-correlation optical flow methods. The model and experimental results are discussed in the context of potential effects on overall fire behavior, and an analogy between merging flames and winddriven single flames is suggested.

\section{Theory}

Fires produce strongly buoyant plumes composed of rapidly ascending gases. Continuity requires this rising fluid mass to be replaced by a horizontal inflow. For line fires, the inflow is primarily perpendicular to the fire's axis (entrainment at the edges becomes insignificant). As two line fires converge, flow on the inboard side of each flame (nearest to the neighboring flame) is restricted, resulting in asymmetric entrainment. This leads to an imbalance of forces acting on the fire plume, causing it to tilt in the direction of least inflow velocity.

A two-dimensional slice of a line fire is shown in Figure 3. We assume the fire is a fully developed turbulent diffusion flame. If the control volume surrounding the flame is of height $L$, width $D$, and depth (into the page) $W$, the plume angle from vertical can be estimated as

$$
\theta=\tan ^{-1}\left(\frac{F_{Y}}{F_{Z}}\right)
$$

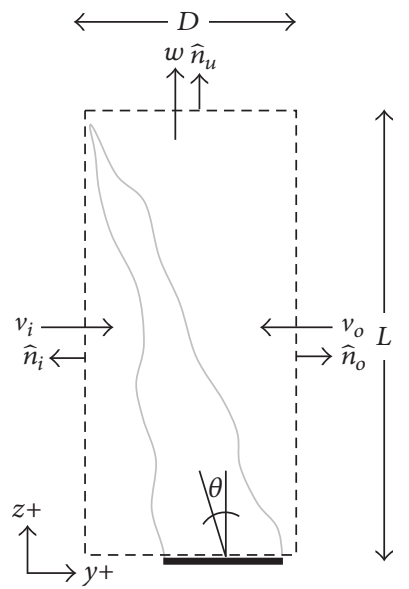

Figure 3: Control volume for momentum balance.

where $F_{Y}$ and $F_{Z}$ represent the horizontal and vertical forces acting on the control volume, respectively. These forces can be determined using the conservation of linear momentum:

$$
\begin{aligned}
F_{Y}= & \frac{\partial}{\partial t}\left[\int_{V} \rho_{o} v_{o} d V+\int_{V} \rho_{i} v_{i} d V\right] \\
& +\int_{A} \rho_{o} v_{o}\left(\widehat{n}_{o} \cdot v_{o}\right) d A+\int_{A} \rho_{i} u_{i}\left(\widehat{n}_{i} \cdot v_{i}\right) d A \\
F_{Z}= & \frac{\partial}{\partial t}\left[\int_{V} \rho_{p} w_{o} d V\right]+\int_{A} \rho_{p} w\left(\widehat{n}_{u} \cdot w\right) d A,
\end{aligned}
$$

where $v$ and $w$ are the components of horizontal and vertical velocity, respectively, $\rho$ is the fluid density, and subscripts $o$, $i$, and $p$ represent the outboard, inboard, and interior regions of the plume, respectively. If we assume that all inflows and outflows are steady (implying that the fire has achieved quasisteady state and is not influenced by variations in atmospheric flow), that combusting fuel vapor enters the control volume with negligible momentum, and that the ambient density on the inner side (inboard) of the flame is equivalent to the outside, (2) can be simplified and expressed as force per unit length of flame front:

$$
\begin{aligned}
& F_{Y}^{\prime}=\rho_{o} L\left(v_{o}{ }^{2}-v_{i}^{2}\right), \\
& F_{Z}^{\prime}=\rho_{P} D w^{2} .
\end{aligned}
$$

Flame angle is then represented as

$$
\tan \theta=A\left(\frac{v_{e}^{2}}{w^{2}}\right),
$$

where $v_{e}$ is the "excess" inflow velocity from the outboard edge

$$
v_{e}=\sqrt{v_{o}^{2}-v_{i}^{2}}
$$

and $A$ is a dimensionless parameter

$$
A=\frac{\rho_{o} L}{\rho_{p} D} .
$$


Although $D$ is the width of the control volume, it is also approximately the width of the base of the flame. $L / D$ for flames has been related to heat release rate for a number of fire configurations $[30,31]$, most commonly to $Q_{D}^{* 2 / 5}$, where $Q_{D}^{*}$ is the dimensionless heat release rate:

$$
Q_{D}^{*}=\frac{\dot{Q}}{\rho_{0} c_{p} T_{0} \sqrt{g} W D^{3 / 2}},
$$

where $\dot{Q}$ is the rate of heat release and $\rho_{0}, c_{p}$, and $T_{0}$ are the density, specific heat, and temperature of ambient air, respectively. Sugawa et al. [32] performed experiments on interacting line fires with gas burners and showed that $L / D$ is proportional to $Q_{D}^{* 2 / 3}$. For natural fires, $Q_{D}^{*}$ ranges from approximately 0.1 to 5 [33]. The parameter $A$ can then be expressed as

$$
A \sim \frac{\rho_{o}}{\rho_{p}} Q_{D}^{* n}
$$

and is of order $0.1-1$ for natural fires for $n<1$.

Note that (4) requires the velocities to be known. Since the horizontal inflow is driven by buoyancy, we expect these velocities to be related to the vertical velocity of the plume.

As a first approximation, we propose that the horizontal flow field surrounding the fires is analogous to the potential flow field generated by two adjacent line sinks of fluid. This concept is not new, as Baldwin et al. [17] mentioned using potential flow in the study of merging flames by modeling individual fires as point sinks of fluid. The idea was employed by Weihs and Small [34] who studied the interaction of fire plumes by modeling each fire as a vertical distribution of point sinks (in the flaming region) and point sources (in the upper "thermal plume" region). Additionally, the existence of sink-like inflow near fires is supported by Smith et al. [28], who studied natural convection above strongly heated line sources of finite width but infinite length. More recently, Kaye and Linden [35] used potential flow to approximate the entrainment field surrounding adjacent axisymmetric plumes. Since a line sink can be approximated as a series of closely spaced point sinks, this is a natural extension of this concept. Lu et al. [11] also proposed that the interaction of merging façade flames is due to interactions of the potential flows generated by the fires' entrainment fields.

An incompressible potential flow field is one which satisfies Laplace's equation. Since solutions to Laplace's equation can be linearly combined, the solutions of multiple flow features (sources, sinks, uniform flows, etc.) can be added to construct the aggregate velocity field [36]. Of course, potential flow is not without its limitations. To satisfy Laplace's equation, the velocity field must be both incompressible and irrotational. Incompressibility is a reasonable assumption; though the combustion process itself is one of rapid expansion, the flow field surrounding the fire is of minimal velocity. Irrotationality, however, is more difficult to justify. The flow field surrounding fires often exhibits rotation at multiple scales. This is evident by the well-organized convection columns observed above large fires and by the existence of fire whirls, highly rotational vertical columns of combusting

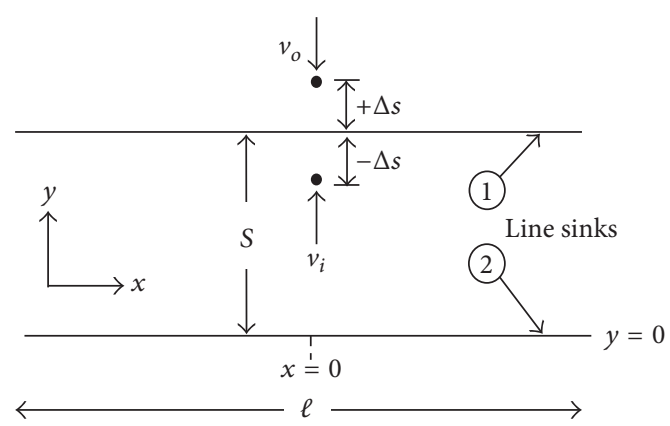

FIGURE 4: Schematic for potential flow of two adjacent line sinks.

gas. However, large convection columns only appear to play a significant role for very large fires or groups of fires [2] which are beyond the scope of this study. Moreover, fire whirls and other vortices are highly transient, so it may be argued that potential flow represents an average velocity field which is periodically perturbed by these local events.

This complex potential for a distributed line sink, which consists of an infinite number of closely spaced point sinks distributed over a defined length, is given by Paraschivoiu [37]:

$$
\phi(z)=\frac{-k}{2 \pi \ell}[z \ln z-(z-\ell) \ln (z-\ell)],
$$

where $z$ is the complex number $x+i y, \ell$ is the length of the line sink, and $k$ is the strength of the sink. The derivative of (9) yields the complex velocity:

$$
V(z)=\frac{d \phi}{d z}=\frac{-k}{2 \pi \ell} \ln \frac{z}{z-\ell},
$$

where $V=u-i v$, and $u$ and $v$ are the components of velocity parallel and normal to the line sink, respectively. The complex velocity for two neighboring line sinks is

$$
\begin{aligned}
V(z) & =\frac{d \phi_{1}}{d z}+\frac{d \phi_{2}}{d z} \\
& =\frac{-k}{2 \pi \ell}\left[\ln \left(\frac{z_{1}}{z_{1}-\ell}\right)+\ln \left(\frac{z_{2}}{z_{2}-\ell}\right)\right],
\end{aligned}
$$

where subscripts 1 and 2 reference the line sinks shown in Figure 4 and $k / \ell$ is the strength of the sink per unit length, which has units of velocity. Physically, $k / \ell$ represents the amount of fluid terminating in the sink per unit length per unit time. In a fire, buoyancy causes fluid to rise with velocity $w$. This rising fluid acts as a sink since it has to be replaced through the horizontal inflow. Thus, for fires, we make the assumption that $k / \ell$ is equivalent to the vertical velocity of the fire plume, $w$.

The effect of separation distance on the potential flow field for two distributed line sinks is shown in Figures 5 and 6. Each line sink draws in fluid from all directions at a constant rate. As the separation distance between lines decreases, the magnitude of the inboard velocity component normal to the line sink is reduced. To satisfy continuity, this decrease is 

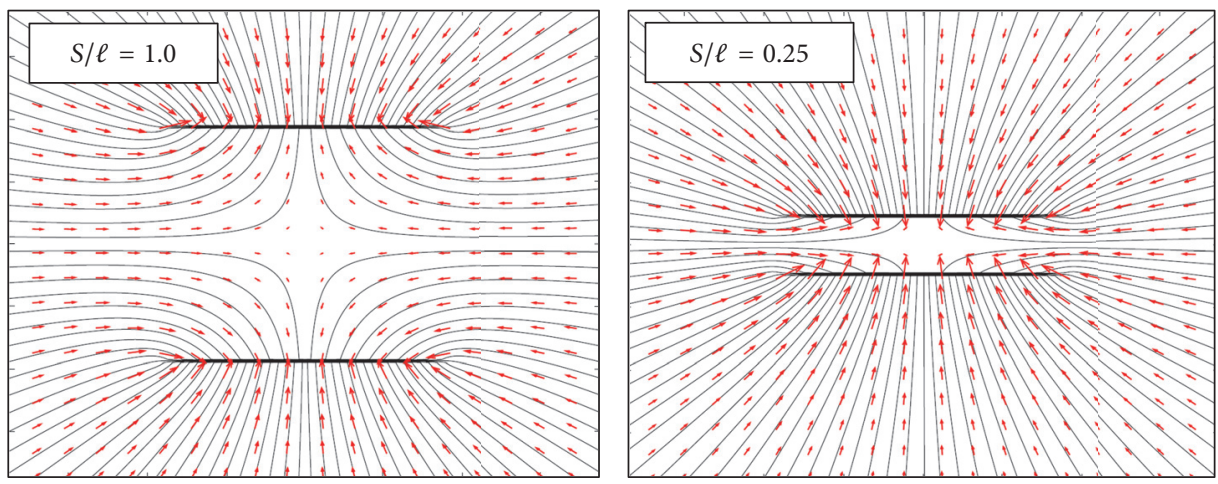

FiguRE 5: Streamlines and velocity field for two converging line sinks.

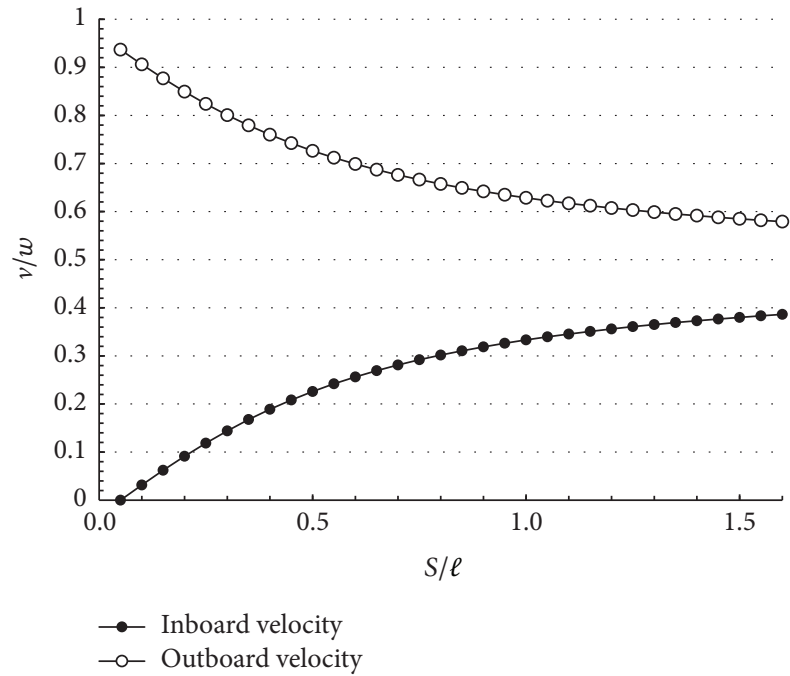

Figure 6: Potential flow model: effect of separation distance on inboard and outboard velocities normal to the line sink at $x=0$, normalized to vertical velocity.

balanced by an increase in flow velocity on the outside of the sink (Figure 6). Since the magnitude of the inflow velocity is proportional to the source strength, the velocity difference across each line sink normalized to vertical velocity is a function of $S / \ell$ only.

Qualitatively, the velocity difference can be explained by considering the path of fluid parcels as they enter the region between sinks. As shown in Figure 5, streamlines entering the central region are nearly parallel to the sinks, and parcels enter the region with almost no $y$-component of velocity. Once the parcel is between the sinks it will start accelerating towards the nearest one. As the separation distance decreases, so does the length scale of parcel acceleration, which ultimately limits the inboard velocity. Additionally, the neighboring fire imposes a horizontal pressure gradient force which opposes parcel acceleration, further reducing velocity.

\section{Experiments}

3.1. Experimental Setup. To investigate the validity of the proposed model for merging flames, experiments were performed to measure the velocity field surrounding stationary line fires. A schematic of the experiment is shown in Figure 7. Two rectangular steel pans $(\ell=150 \mathrm{~cm}, D=7 \mathrm{~cm})$, each containing equal volumes of liquid fuel (isopropyl alcohol, $91 \%$ by volume), were placed next to each other at six different separation distances, from $S / \ell$ of 0.1 to 1.5 . For line fires, Yuan and Cox [38] give a functional relationship between flame length and heat release rate per unit length:

$$
L_{f}=0.034 \dot{Q}_{L}^{2 / 3},
$$

where $L_{f}$ is the total length of flame (m) (equal to $L$ for vertical flames) and $\dot{Q}_{L}$ is the heat release rate per unit length $(\mathrm{kW} / \mathrm{m})$. For the flame lengths observed in our experiments, (10) yields a heat release rate per unit length of approximately $50 \mathrm{~kW} / \mathrm{m}$, which is in the low range of intensity for vegetation fires in surface fuels [39].

For each separation distance, the behavior of the leftmost fire was captured by a high-definition video camera with a frame rate of 30 frames per second (standard frame rate for a consumer-grade video camera), with the fire placed directly in the center of the frame. Prior to testing, the frame was spatially calibrated (using a meter stick) to determine the linear dimension per pixel at the center of the fire. To visualize the surrounding flow field, colored smoke cartridges (ammonium chloride/potassium chlorate) were placed on both sides of the fire (Figure 8). The high-contrast smoke from cartridges made it easy to identify fluid structures as they were drawn into the fire plumes. Each fire was ignited simultaneously and allowed to burn for at least 10 seconds prior to capture. Although 10 seconds was the minimum, many were allowed to burn for a period closer to 30 seconds prior to video capture. Video was captured for approximately 60 seconds during the steady burning period.

3.2. Analysis. To obtain the best possible insight into merging fire entrainment, a method of nonintrusive quantitative 


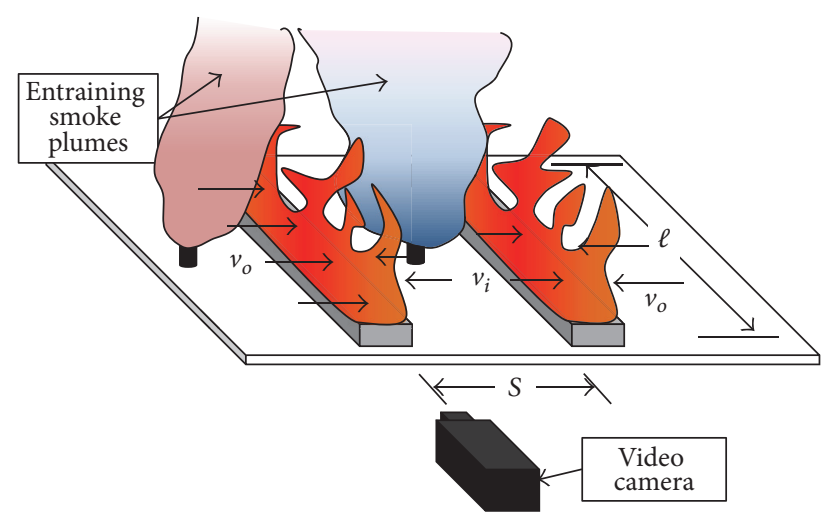

FIGURE 7: Schematic of pool fire experiments. Pool fires were seeded by colored smoke plumes which were entrained into the regions surrounding the flames.

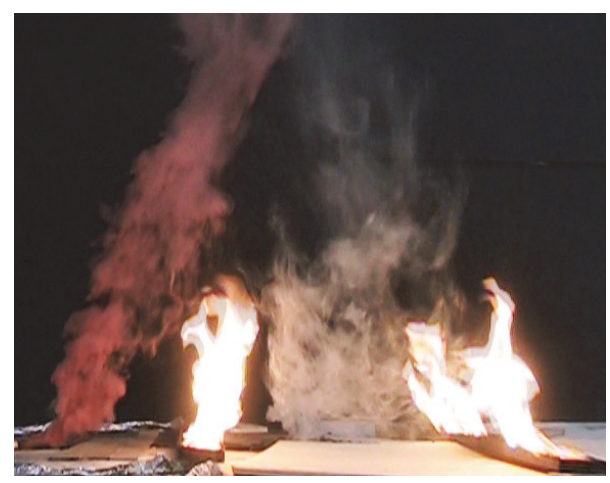

Figure 8: Use of smoke cartridges for flow field visualization. Exaggerated flame angle on right is fictitious, due to perspective distortion (figure is cropped; camera is actually centered on left fire).

visualization capable of determining the entire velocity field over a relatively large region was desired. One common technique for this is particle image velocimetry (PIV). In PIV, the velocity field is "seeded" by reflective particles which are assumed to follow the flow. A pulsed laser is used to illuminate the particles in a thin plane, and two images are then captured in rapid succession. The images are compared to determine particle displacement using a cross-correlation algorithm, yielding the velocity field [40]. PIV has successfully been deployed on pool fires [41] as well as for fires in vegetative fuel beds [42]. However, for the scale of the present experiments, PIV has several distinct limitations. The spatial resolution of PIV is directly related to the size, density, and homogeneity of seeding particles. In our case, the region of interest spans several meters (both horizontally and vertically), which presents severe difficulties in obtaining adequate particle density and exceeds the size of plane produced by the focused lasers. Since our goal was to determine the bulk motion of the entrainment field over a large region, we determined that PIV would not be the ideal option. Instead, we chose to pursue a more general "optical flow" analysis, of which PIV may be considered a specialized type.
The optical flow field is the velocity field which results from the motion of an object within an image frame. Though numerous classes of optical flow methods exist, the two most common approaches involve the gradient-based analysis of a conserved image signal [43] and the cross-correlation of image features [40]. Cross-correlation has been used to obtain the time-averaged velocity field for plumes with high visible contrast consisting of discrete fluid structures which rotate, translate, and deform as they rise, namely, ocean hydrothermal vents [44]. These plumes are analogous to the smoke used for flow visualization in our experiments. In our case, the smoke originates from a point source (the cartridge) but rapidly assimilates to the local flow field. In crosscorrelation optical flow, the image cross-correlation coefficient is defined as

$$
C_{f g}(m, n)=\sum_{i} \sum_{j} f(i, j) \times g(i+m, j+n),
$$

where $f(i, j)$ and $g(i, j)$ are the image intensity distributions in the first and second images, respectively, and $m$ and $n$ are the pixel offsets between each image. Essentially, the crosscorrelation function attempts to match the progression of image features from frame to frame. Images are parsed into interrogation regions which are compared between frames of known $\Delta t$. The displacement vector is then calculated by finding the displacement of the correlation peak between frames, that is, the locations where the regions best match each other. A similar technique using thermal images from IR cameras was used to estimate flow fields within a flame [45].

\subsection{Experimental Methods}

3.3.1. Velocity Field. For each experiment, three separate intervals, each with a duration of five seconds (150 frames), were analyzed. For each separation distance, the experiment was replicated three times to estimate error. Image analysis was performed using OpenPIV [46], an open-source crosscorrelation algorithm designed for use with PIV imagery. For each capture, three separate regions, outboard, inboard, and upper (Figure 9), were analyzed to determine the relevant velocity fields. The inboard and outboard regions extended laterally from the location of the respective smoke cartridge $(25 \mathrm{~cm}$ from the reservoir) to the approximate flame edge and vertically to the approximate flame tip. The upper plume region was located directly above the flame tip and spanned several flame widths. Each region was approximately $200 \times$ 200 pixels. An interrogation window of $32 \times 32$ pixels and an overlap of $8 \times 8$ pixels were used for the cross-correlation analysis.

The mean velocity fields were obtained by taking the average of the instantaneous fields over the capture duration (five seconds). For the horizontal inflow (outboard and inboard), the mean velocity value was determined by taking the average value of the horizontal velocity profile from the base of the flame to its tip, directly next to the flame. Vertical velocity was determined by taking the maximum value of the vertical velocity in a horizontal plane at the top of the intermittent flame zone, as defined by McCaffrey [47]. 


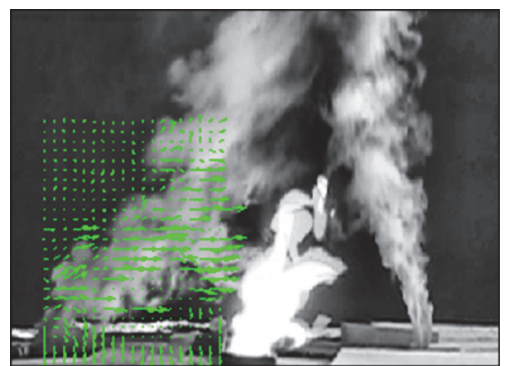

(a)

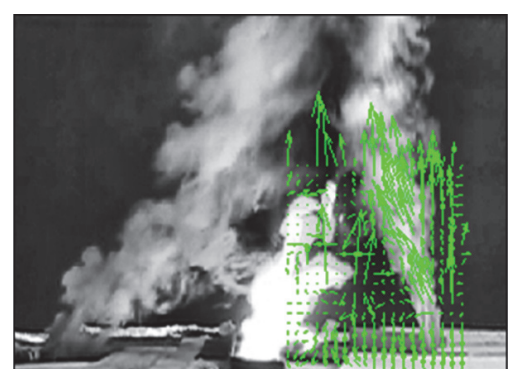

(b)

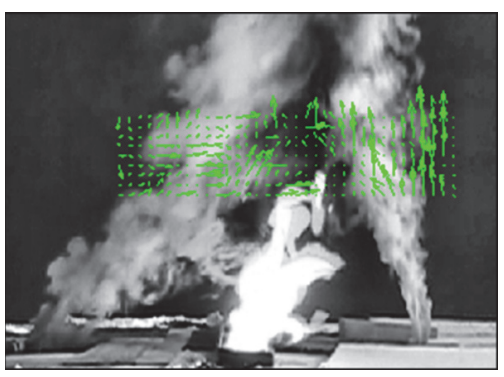

(c)

Figure 9: Outboard (a), inboard (b), and upper (c) plume instantaneous velocity fields from OpenPIV processing.

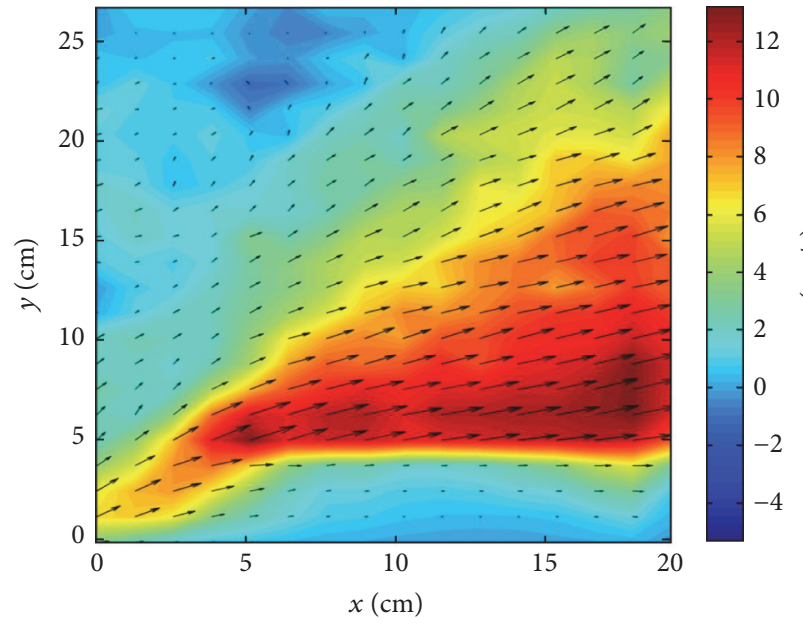

(a)

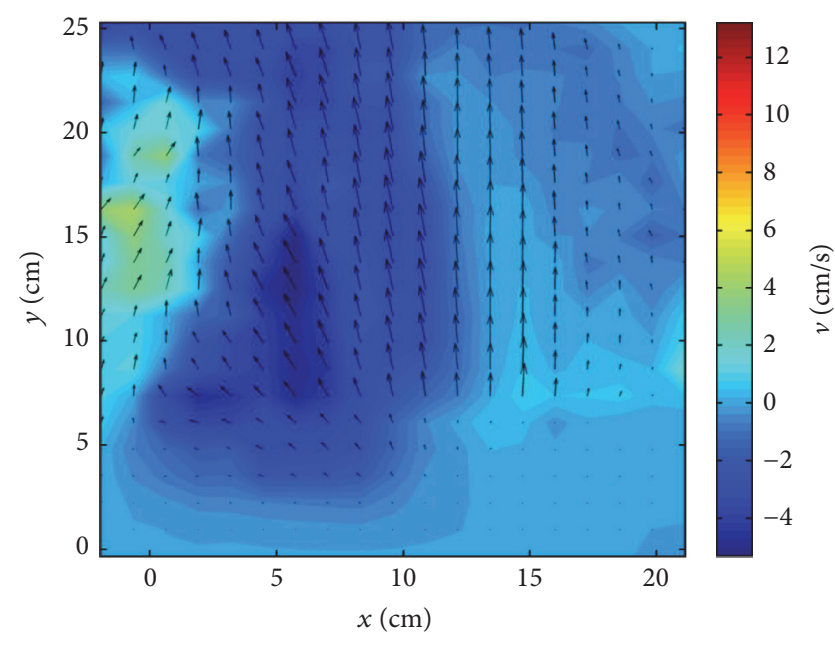

(b)

Figure 10: Time-averaged outboard (a) and inboard (b) velocity fields for $S / H_{S}=3.25$ ( $H_{S}=$ height of single flame). Duration of averaging period is 5 seconds.

3.3.2. Flame Height and Angle. Mean flame height and angle were determined by analyzing the spatially calibrated video frames. Since the flame's brightness was much greater than the smoke and background, an algorithm was used to identify the location of the flame boundary in each frame by searching for continuous regions of maximum pixel intensity. Similar methods have been used to determine statistical properties of flame geometry and luminous intensity [48, 49]. However, this method was not amenable to determining flame angle, since the flame shape is irregular, making it difficult to detect a horizontal midpoint at the flame tip. Instead, flame angle was determined by measuring the angle between a line parallel to the flame's axis and a line normal to the surface; this was done for five sample frames per capture via image processing software. The length of the flame $\left(L_{f}\right)$ was calculated from the flame height and angle [50]:

$$
L_{f}=\frac{H}{\cos \theta},
$$

where $H$ is the maximum height of visible flame above the surface.

\section{Results}

4.1. Velocity Field. An example of the time-averaged outboard and inboard velocity fields is shown in Figure 10. Data is shown for the separation distance relative to the height of a single flame of $3.25\left(S / H_{S}=3.25\right)$. For the outboard plume, horizontal inflow velocities of approximately $10 \mathrm{~cm} / \mathrm{s}$ were present for all experiments, which is comparable to the values measured by Zhou and Gore [51] using laser Doppler velocimetry around a $7.1 \mathrm{~cm}$ toluene pool fire. Mean outboard and inboard velocities normalized to vertical velocity as a function of $S / H_{S}$ are presented in Figure 11. As expected, the velocity on the inboard side of the flame was lower and decreased with decreasing separation distance, while the outboard velocity increased slightly (Figure 11). For the smallest separation distance $\left(S / H_{S}=0.3\right)$, flames were almost completely merged. For this case, inboard velocity could not be measured but was assumed to be zero. Immediately evident is the existence of a velocity differential at even the largest separation $\left(S / H_{S}=5\right)$, which suggests that fire interactions can begin to occur at even larger distances. Overall, the data agree reasonably with the behavior predicted by the potential flow model, except at the smallest separation distance 


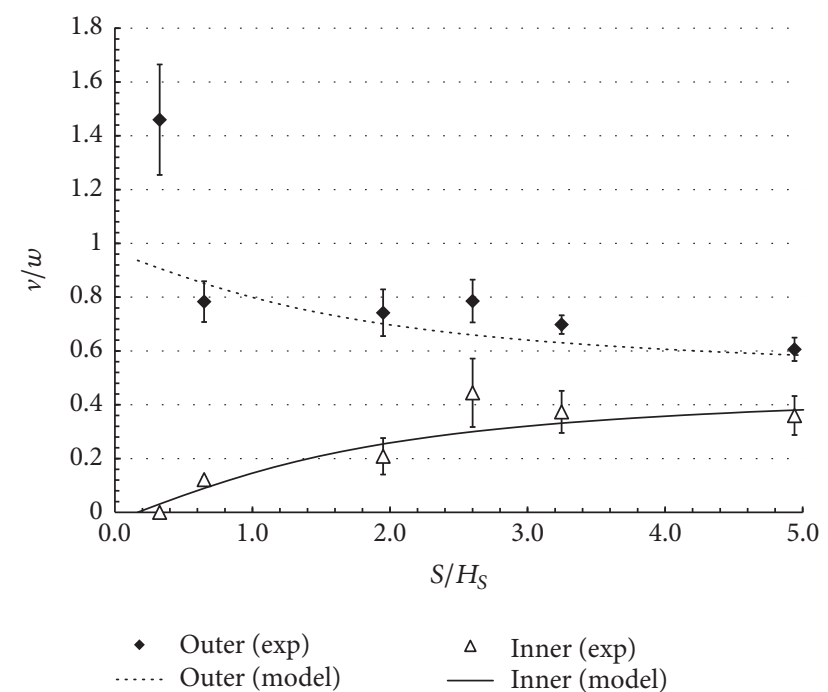

FIGURE 11: Mean outboard and inboard velocities normalized to vertical velocity. Error bars represent one standard deviation of the mean.

$\left(S / H_{S}=0.3\right)$. At this distance, the flames are fully merged at a short distance above the surface, and the inboard edge of the flame can no longer entrain in the $y$-direction above the merging height. Comparison of vertical and inflow velocities for the merged plume becomes more complicated, since they are both dependent on the degree of merging. Two fully merged plumes of equal strength have twice the buoyancy flux of each plume [50], but this is not necessarily manifest in the vertical velocity, since destructive interference between plumes may cause it to decrease [52].

Vertical velocity increased slightly with decreasing separation distance, until $S / H_{S}<2$, below which it decreased rapidly (Figure 12). This is likely an effect of burning rate, which is proportional to the heat release rate (HRR) of the fire [53]. For line plumes, vertical velocity scales with buoyancy flux, and thus HRR, to the $1 / 3$ power. As discussed by Liu et al. [9], as proximate pool fires approach each other, augmented radiant feedback accelerates burning. However, as separation distance becomes very small, entrainment becomes restricted and burning rate decreases. Our measurements of vertical velocity appear to agree with this notion, though burning rate was not explicitly measured.

4.2. Flame Angle. Observed flame angle versus $v_{e}{ }^{2} / w^{2}$ is shown in Figure 13. Flame angle for the two closest separation distances is not shown since the flames were merged for these experiments. The slope of the linear fit in Figure 13 gives a value of 0.843 for $A$ (see (6)).

Overall, both the observed and measured values (see (4)) agree reasonably with each other and with the angle predicted by potential flow for most of the experimental range but diverge from the model as the flames begin to merge (Figure 14). This is to be expected, since at small separation distances, $S / H_{S}<2$, the flames are forced to merge with the neighboring buoyant plume, gradually straightening until

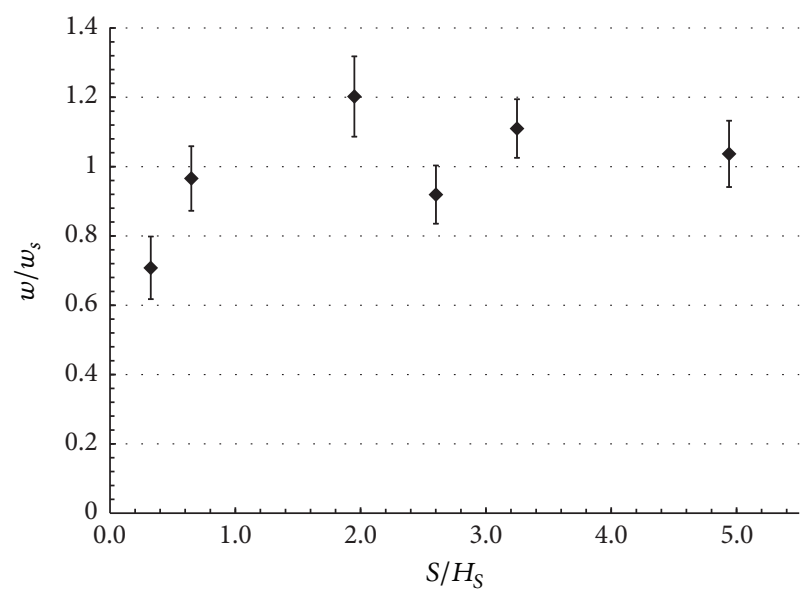

FIgURE 12: Vertical velocity normalized to single flame vertical velocity. Error bars represent one standard deviation of the mean.

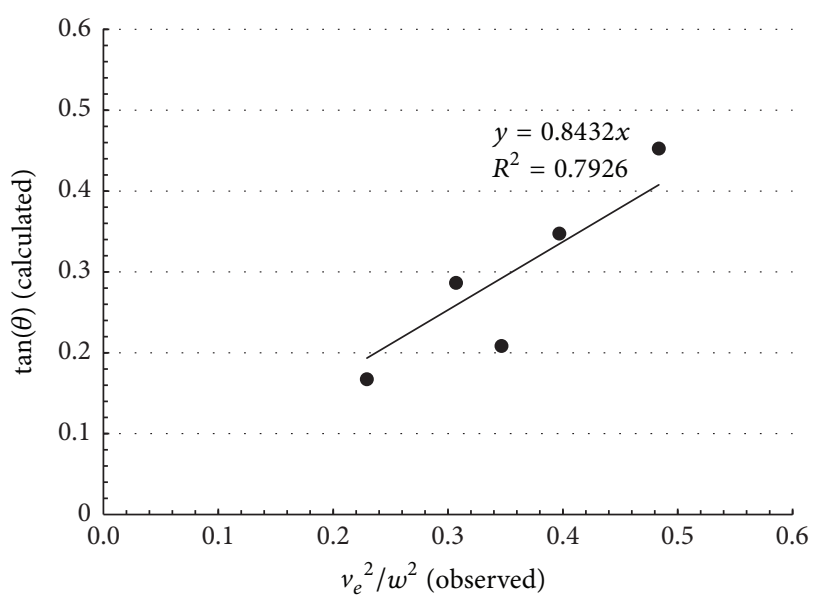

FIGURE 13: Observed flame angle versus $v_{e}^{2} / w^{2}$ for nonmerged separation distances.

they eventually return to the vertical as a fully merged, single plume.

4.3. Flame Length. In general, flame length was not significantly affected by interaction (Figure 15). This differs from the results obtained by other researchers using gas burners, who observed increases in flame length as fires converged $[12,54]$. However, in their studies, the burning rate was kept constant. For freely burning pool fires, burning rate is not controlled. For line fires, flame length is related to heat release rate, which is proportional to the burning rate. As mentioned above, from our measurements of vertical velocity, it was inferred that burning decreased as the flames began to merge. Thus, the potential increase in flame length due to merging effects was masked by the reduced burning rate. This issue is worthy of further study, since flame lengths are observed to increase in merging vegetation fires, where burning rate is inherently coupled with fire behavior. 


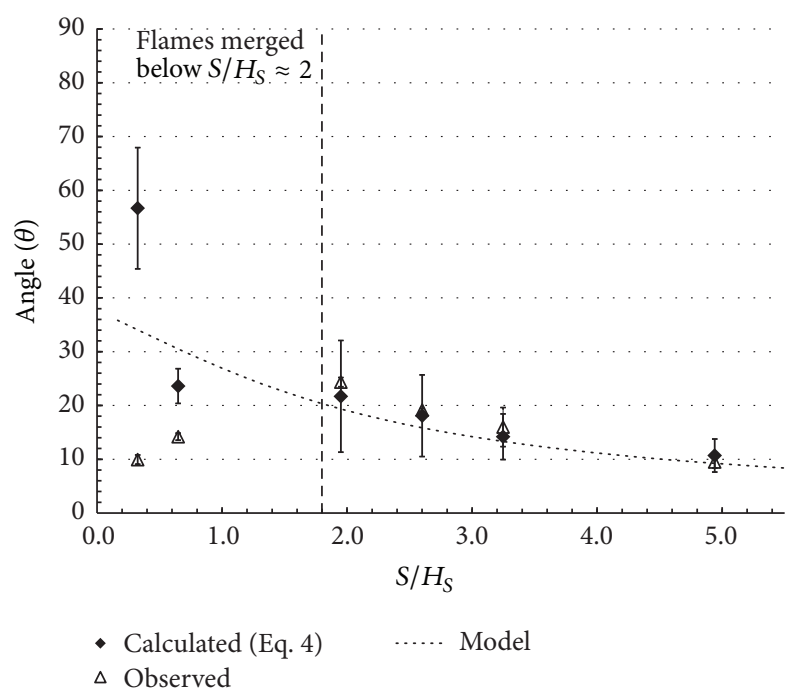

Figure 14: Flame angle versus separation distance. Measured value calculated using $A=0.843$. Flames began to merge at spacing below $S / H_{S}=2$. Error bars represent one standard deviation of the mean. Large uncertainty in measured value is due to the summation of relative uncertainty of the squares of three measured values.

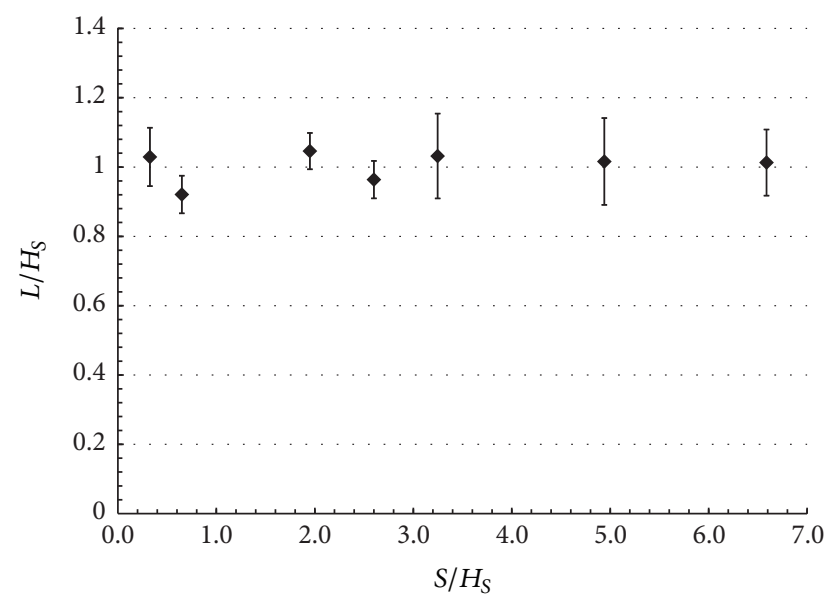

Figure 15: Flame length versus separation distance. Flames began to merge below $S / H_{S}=2$.

\section{Discussion}

5.1. Do Interacting Flames Become "Wind-Blown" Flames? Many of the effects observed during fire merging are similar to those which occur with single flames burning under the influence of an ambient wind, including increased flame angle and rate of spread $[50,55]$. As mentioned in the introduction, wind can have a marked effect on fire behavior.

The model and experiments discussed in this paper suggest that converging line fires are subject to nonuniform entrainment as a result of their position relative to each other. This leads to the development of a velocity difference normal to each flame front, causing the flame angle to depart from vertical. Of interest is whether this velocity difference has the same effect as an ambient wind of equal magnitude, which could suggest that merging flames may transition to "winddriven" fire behavior as their separation distance reaches a critical value.

At present, there is no universally accepted definition for what constitutes a wind-driven fire. Byram [55] made one of the earliest attempts to classify fire behavior relative to the influence of ambient wind. He introduced the convection number:

$$
N_{C}=\frac{2 g I}{\rho_{a} c_{p} T_{a} u_{a}{ }^{3}},
$$

where $I$ is the fireline intensity (energy released per unit length of fire front), $\rho_{a}$ is the density of ambient air, $c_{p}$ is the specific heat of air at constant pressure, $T_{a}$ is the ambient air temperature, and $u_{a}$ is the ambient wind velocity. The convection number represents the rate at which thermal energy is converted to kinetic energy in the convection column ("power of the fire") relative to the horizontal flux of kinetic energy from the mean flow ("power of the wind"). Based on analysis of several large fires, Rothermel [47] used a convection number of unity to differentiate between plume (buoyancy) dominated and wind-driven fires. The convection number for a line fire can be represented as the inverse of a Froude number based on buoyancy flux $[50,56,57]$ :

$$
F_{R}=\frac{u_{a}^{3}}{b_{F}}=2 N_{C}^{-1},
$$

where $b_{F}$ is the buoyancy flux per unit length of source:

$$
b_{F}=\frac{g I}{\rho_{a} c_{p} T_{a}}=\frac{u_{a}{ }^{3} N_{c}}{2} .
$$

Nelson et al. [57] derived (16) by relating line fire plumes with those from ocean outfall diffusers, which were studied by Roberts [58]. Based on his analysis and experiments, he proposed three distinct regimes for line plumes subject to a mean flow. For small Froude numbers $(F R<0.2)$, the plume is dominated by buoyancy and the flow is strongly vertical. For large Froude numbers (FR $>1$ ), there is an excess of inflow, forcing the plume to stay attached to the surface and propagate downstream. The intermediate regime $(0.2<\mathrm{FR}<$ 1) represents a transition between the two extremes. Nelson et al. [57] applied this criterion to line fires. Using (16), they proposed that $N_{C}>10$ implies that wind has a minimal effect on the fire plume, while $N_{C}<2$ implies a strong wind influence.

Rouse et al. [59] studied interacting turbulent line plumes and showed that the vertical velocity scaled with the buoyancy flux per unit length as

$$
w=b_{F}^{1 / 3} \text {. }
$$

Substitution of this vertical velocity into (16) suggests the convection number for line fires scales as a function of inflow and vertical velocities only:

$$
N_{C} \approx\left(\frac{w}{u_{a}}\right)^{3} .
$$




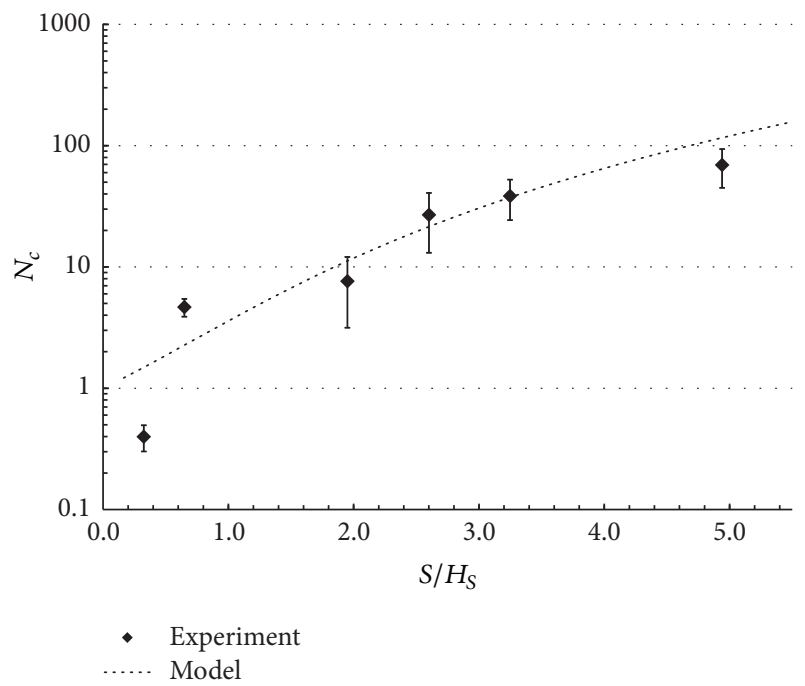

FIGURE 16: Convection number. Error bars represent one standard deviation of the mean.

An identical result can be obtained by substituting the characteristic buoyant velocity for a fire, defined by Nelson Jr. [60]

$$
w_{B}=\left(\frac{2 g I}{\rho_{a} c_{p} T_{a}}\right)^{1 / 3}
$$

into the first equality of (17). If we assume the asymmetric entrainment caused by fire convergence to have the same effect as an ambient wind of equal magnitude, then the convection number can be represented a function of $S / H$ :

$$
N_{C}=\left(\frac{w}{v_{o}-v_{i}}\right)^{3}=f\left(\frac{S}{H}\right)
$$

Using (21), the convection number from our experiments is plotted in Figure 16. Using the abovementioned criteria, the transition to wind-driven fire behavior in our experiments begins at $S / H \sim 1$. It must be mentioned that the convection number was developed as a metric to study the behavior of convection columns above large fires. As such, it was originally derived using a complex coupled atmosphere/thermodynamic model [60, 61], effects which are clearly not considered in our analysis. However, its representation as a function of buoyancy flux clearly illustrates its local importance on the behavior of wind-driven flames, as indicated by the experiments of Nelson Jr and Adkins [62] and Weise and Biging [56].

\section{Conclusions}

The effects associated with flame interaction are important for both the physical understanding and practical control of fire. This paper developed and validated a simple model to explain flame tilt in merging flames as a result of asymmetric entrainment. Asymmetric entrainment causes flames to tilt as if exposed to an ambient wind, which may explain why interacting fires often exhibit behavior similar to wind-blown flames. The proposed mechanism resulted from an imbalance of horizontal momentum across the flame front caused by flow restriction on the inboard edge of the flame due to the combined effects of reduced acceleration length and the opposing dynamic pressure gradient generated by the neighboring fire. Potential flow was found to be a reasonable assumption for the entrainment field surrounding interacting fires. Crosscorrelation optical flow analysis proved to be a useful method for estimating the flow field surrounding fires; however, this method is inherently less accurate than planar measurement techniques such as particle image velocimetry. Measurements at field scale are recommended to determine if the laboratory results scale to larger, spreading fires such as prescribed burns where ignition patterns intentionally produce merging flame zones. If the similarity of flames from merging line fires with flames from wind-blown fires remains at field scale, simple improvements to existing fire models to include merging fire behavior may be possible.

\section{Nomenclature}

A: Dimensionless parameter $\rho_{o} L / \rho_{p} D$

$b_{f}$ : Buoyancy flux per unit length of source

$C$ : Image cross-correlation coefficient

$c_{p}$ : Specific heat at constant pressure

$D$ : Control volume width

$F$ : Force acting on control volume

$f:$ First image in cross-correlation

$g$ : Second image in cross-correlation

g: Gravitational acceleration constant, $9.81 \mathrm{~m} / \mathrm{s}^{2}$

$H$ : Maximum visible flame height

I: Fireline intensity

$k$ : Strength of line sink

$L$ : Control volume height

$L_{f}$ : Flame length (equal to $L$ for vertical flames)

$\ell$ : Length of line sink

$m$ : Horizontal pixel offset for cross-correlation

$n$ : Vertical pixel offset for cross-correlation

$N_{C}$ : Convection number

$\dot{Q}:$ Heat release rate

$Q_{D}^{*}$ : Dimensionless heat release rate

$S: \quad$ Separation distance between fires

$T: \quad$ Temperature

$u$ : Ambient wind velocity for convection number

$V$ : Complex velocity, $u-i v$, for a distributed line sink

$v$ : Horizontal velocity component

$W$ : Flame depth

$w$ : Vertical velocity component

$z$ : Complex number, $x+i y$

$\theta: \quad$ Fire plume angle (from vertical)

$\rho$ : Density

$\varphi$ : Complex potential for a distributed line sink. 


\section{Subscripts}

a: Ambient condition

$i$ : Inboard region of fire plume

$o$ : Outboard region of fire plume

$p$ : Interior region between fire plumes

$s$ : Single flame

$Y$ : Horizontal ( $y$-direction)

$Z$ : Vertical ( $z$-direction).

\section{Additional Points}

Summary for Table of Contents. The convergence of separate flame fronts is often accompanied by changes in fire behavior. In this paper, a simple fluid entrainment model is used to describe the mechanism of flame tilting for merging line fires. The model was validated with experiments using laboratory scale line fires, and an analogy between merging flames and wind-blown flames is proposed.

\section{Competing Interests}

The authors declare that there is no conflict of interests regarding the publication of this paper.

\section{Acknowledgments}

Financial support for this research was provided by the National PERISHIP Fellowship in Hazards, Risks, and Disasters. Joey Chong of the USDA Forest Service Pacific Southwest Research Station provided a great deal of support during experiments. The authors would also like to thank Christian Bartolome, Stephen Coffer, Mitchell Shinn, Jitmohan Malay, Jahangir Ashraf, Eric Peng, and Shen Ren for their assistance during laboratory experiments.

\section{References}

[1] R. W. Johansen, "Prescribed burning with spot fires in the Georgia Coastal Plain," Georgia Forest Research Paper 49, Georgia Forestry Commission, Macon, Ga, USA, 1984.

[2] M. A. Finney and S. S. McAllister, "A review of fire interactions and mass fires," Journal of Combustion, vol. 2011, Article ID 548328, 14 pages, 2011.

[3] R. E. Martin and J. D. Dell, "Planning for prescribed burning in the inland northwest," General Technical Report GTR-PNW076, USDA Forest Service, Pacific Northwest Forest and Range Experiment Station, Portland, Ore, USA, 1978.

[4] L. R. Green, "Burning by prescription in chaparral," General Technical Report GTR-PSW-051, USDA Forest Service, Pacific Southwest Forest and Range Experiment Station, Berkeley, Calif, USA, 1981.

[5] D. D. Wade, J. D. Lunsford, M. J. Dixon, and H. E. Mobley, "A guide for prescribed fire in southern forests," Technical Publication R8-TP-11, USDA Forest Service, Southern Region, Atlanta, Ga, USA, 1989.

[6] F. A. Albini, "Transport of firebrands by line thermals," Combustion Science and Technology, vol. 32, no. 5-6, pp. 277-288, 2007.

[7] C. M. Countryman, "Mass fires and fire behavior," Research Paper RP-PSW-019, USDA Forest Service, Pacific Southwest
Forest and Range Experiment Station, Berkeley, Calif, USA, 1964.

[8] D. Morvan, C. Hoffman, F. Rego, and W. Mell, "Numerical simulation of the interaction between two fire fronts in grassland and shrubland," Fire Safety Journal, vol. 46, no. 8, pp. 469-479, 2011.

[9] N. Liu, Q. Liu, J. S. Lozano et al., "Global burning rate of square fire arrays: experimental correlation and interpretation," Proceedings of the Combustion Institute, vol. 32, pp. 2519-2526, 2009.

[10] K. G. Huffman, J. R. Welker, and C. M. Sliepcevich, "Interaction effects of multiple pool fires," Fire Technology, vol. 5, no. 3, pp. 225-232, 1969.

[11] K. Lu, L. Hu, M. Delichatsios, F. Tang, Z. Qiu, and L. He, "Merging behavior of facade flames ejected from two windows of an under-ventilated compartment fire," Proceedings of the Combustion Institute, vol. 35, no. 3, pp. 2615-2622, 2015.

[12] K. Kuwana, S. Kato, A. Kosugi, T. Hirasawa, and Y. Nakamura, "Interaction of two micro-slot flames: heat release rate and flame shape," Journal of Physics: Conference Series, vol. 557, no. 1, Article ID 012079, 2014.

[13] O. Sugawa and W. Takahashi, "Flame height behavior from multi-fire sources," Fire and Materials, vol. 17, no. 3, pp. 111-117, 1993.

[14] S. Schälike, K. B. Mishra, K.-D. Wehrstedt, and A. Schönbucher, "Limiting distances for flame merging of multiple n-heptane and di-tert-butyl peroxide pool Fires," Chemical Engineering Transactions, vol. 32, pp. 121-126, 2013.

[15] G. M. Byram, H. B. Clements, M. E. Bishop, and R. M. Nelson Jr., "Final report-Project Fire Model: an exploratory study of model fires," Contract OCD-PS-65-40, USDA Forest Service, Southeastern Forest Experiment Station, Office of Civil Defense, Asheville, NC, USA, 1966.

[16] P. G. Baines, "Physical mechanisms for the propagation of surface fires," Mathematical and Computer Modelling, vol. 13, no. 12, pp. 83-94, 1990.

[17] R. Baldwin, P. H. Thomas, and H. G. G. Wraight, "The merging of flames from separate fuel beds," Fire Research Note 551, Boreham Wood Fire Research Station, Borehamwood, UK, 1964.

[18] L. Pera and B. Gebhart, "Laminar plume interactions," Journal of Fluid Mechanics, vol. 68, no. 2, pp. 259-271, 1975.

[19] P. Jiang and S. X. Lu, "Pool fire mass burning rate and flame tilt angle under crosswind in open space," Procedia Engineering, vol. 135, pp. 260-273, 2016.

[20] L. Hu, S. Liu, J. L. De Ris, and L. Wu, "A new mathematical quantification of wind-blown flame tilt angle of hydrocarbon pool fires with a new global correlation model," Fuel, vol. 106, pp. 730-736, 2013.

[21] L. Hu, C. Kuang, X. Zhong, F. Ren, X. Zhang, and H. Ding, "An experimental study on burning rate and flame tilt of optical-thin heptane pool fires in cross flows," Proceedings of the Combustion Institute, 2016.

[22] F. Tang, L. J. Li, K. J. Zhu, Z. W. Qiu, and C. F. Tao, "Experimental study and global correlation on burning rates and flame tilt characteristics of acetone pool fires under cross air flow," International Journal of Heat and Mass Transfer, vol. 87, pp. 369375,2015

[23] J. W. Wang, J. Fang, S. B. Lin, J. F. Guan, Y. M. Zhang, and J. J. Wang, "Tilt angle of turbulent jet diffusion flame in crossflow and a global correlation with momentum flux ratio," Proceedings of the Combustion Institute, 2016. 
[24] X. Zhang, W. Xu, L. Hu, and X. Liu, "A new mathematical method for quantifying trajectory of buoyant line-source gaseous fuel jet diffusion flames in cross air flows," Fuel, vol. 177, pp. 107-112, 2016.

[25] F. Tang, L. Li, Q. Wang, and Q. Shi, "Effect of cross-wind on near-wall buoyant turbulent diffusion flame length and tilt," Fuel, vol. 186, pp. 350-357, 2016.

[26] F. Tang, L. Hu, X. Zhang, X. Zhang, and M. Dong, "Burning rate and flame tilt characteristics of radiation-controlled rectangular hydrocarbon pool fires with cross air flows in a reduced pressure," Fuel, vol. 139, pp. 18-25, 2015.

[27] H. Wan, J. Ji, K. Li, X. Huang, J. Sun, and Y. Zhang, "Effect of air entrainment on the height of buoyant turbulent diffusion flames for two fires in open space," Proceedings of the Combustion Institute, 2016.

[28] R. K. Smith, B. R. Morton, and L. M. Leslie, "Role of dynamic pressure in generating fire wind," Journal of Fluid Mechanics, vol. 68, no. 1, pp. 1-19, 1975.

[29] B. R. Morton, G. Taylor, and J. S. Turner, "Turbulent gravitational convection from maintained and instantaneous sources," Proceedings of the Royal Society of London, Series A: Mathematical, Physical and Engineering Sciences, vol. 234, pp. 1-23, 1956.

[30] E. E. Zukoski, "Fluid dynamics of room fires. Fire safety science," in Proceedings of the 1st International Symposium, Washington, DC, USA, 1986.

[31] Y. Hasemi and T. Tokunaga, "Flame geometry effects on the buoyant plumes from turbulent diffusion flames," Fire Science and Technology, vol. 4, no. 1, pp. 15-26, 1984.

[32] O. Sugawa, H. Satoh, and Y. Oka, "Flame height from rectangular fire sources considering mixing factor," in Proceedings of the 3rd International Symposium on Fire Safety Science, vol. 3, pp. 435-444, Tokyo, Japan, 1991.

[33] B. J. McCaffrey, "Purely buoyant diffusion flames: some experimental results," Tech. Rep. NSBIR 79-1910, National Institute for Standards and Technology Report, Washington, DC, USA, 1995.

[34] S. D. Weihs and R. D. Small, "Interactions and spreading of adjacent large area fires," Pacific-Sierra Research Technical Report DNA-TR-86-214, 1986.

[35] N. B. Kaye and P. F. Linden, "Coalescing axisymmetric turbulent plumes," Journal of Fluid Mechanics, vol. 502, pp. 41-63, 2004.

[36] R. E. Meyer, Introduction to Mathematical Fluid Dynamics, Dover, Toronto, Canada, 1982.

[37] I. Paraschivoiu, Subsonic Aerodynamics, Presses Internationals Polytechnique, Montréal, Canada, 2003.

[38] L.-M. Yuan and G. Cox, "An experimental study of some line fires," Fire Safety Journal, vol. 27, no. 2, pp. 123-139, 1996.

[39] M. E. Alexander and M. G. Cruz, "Interdependencies between flame length and fireline intensity in predicting crown fire initiation and crown scorch height," International Journal of Wildland Fire, vol. 21, no. 2, pp. 95-113, 2012.

[40] R. J. Adrian, "Particle-imaging techniques for experimental fluid mechanics," Annual Review of Fluid Mechanics, vol. 23, no. 1, pp. 261-304, 1991.

[41] S. R. Tieszen, T. J. O’Hern, R. W. Schefer, E. J. Weckman, and T. K. Blanchat, "Experimental study of the flow field in and around a one meter diameter methane fire," Combustion and Flame, vol. 129, no. 4, pp. 378-391, 2002.

[42] J. Lozano, W. Tachajapong, D. R. Weise, S. Mahalingam, and M. Princevac, "Fluid dynamic structures in a fire environment observed in laboratory-scale experiments," Combustion Science and Technology, vol. 182, no. 7, pp. 858-878, 2010.
[43] B. K. P. Horn and B. G. Schunck, "Determining optical flow," Artificial Intelligence, vol. 17, no. 1-3, pp. 185-203, 1981.

[44] T. J. Crone, R. E. McDuff, and W. S. D. Wilcock, "Optical plume velocimetry: a new flow measurement technique for use in seafloor hydrothermal systems," Experiments in Fluids, vol. 45, no. 5, pp. 899-915, 2008.

[45] X. Zhou, L. Sun, S. Mahalingam, and D. R. Weise, “Thermal particle image velocity estimation of fire plume flow," Combustion Science and Technology, vol. 175, no. 7, pp. 1293-1316, 2003.

[46] Z. J. Taylor, R. Gurka, G. A. Kopp, and A. Liberzon, "Longduration time-resolved PIV to study unsteady aerodynamics," IEEE Transactions on Instrumentation and Measurement, vol. 59, no. 12, pp. 3262-3269, 2010.

[47] B. J. McCaffrey, "Purely buoyant diffusion flames: some experimental results," National Institute for Standards and Technology Report NSBIR 79-1910, National Institute for Standards and Technology, Washington, DC, USA, 1979.

[48] L. Audouin, G. Kolb, J. L. Torero, and J. M. Most, "Average centreline temperatures of a buoyant pool fire obtained by image processing of video recordings," Fire Safety Journal, vol. 24, no. 2, pp. 167-187, 1995.

[49] T. Maynard and M. Princevac, "The application of a simple free convection model to the pool fire pulsation problem," Combustion Science and Technology, vol. 184, no. 4, pp. 505-516, 2012.

[50] F. A. Albini, "A model for the wind-blown flame from a line fire," Combustion and Flame, vol. 43, pp. 155-174, 1981.

[51] X. C. Zhou and J. P. Gore, "Air entrainment flow field induced by a pool fire," Combustion and Flame, vol. 100, no. 1-2, pp. 52-60, 1995.

[52] R. W. Macdonald, R. K. Strom, and P. R. Slawson, "Water flume study of the enhancement of buoyant rise in pairs of merging plumes," Atmospheric Environment, vol. 36, no. 29, pp. 46034615, 2002.

[53] D. Drysdale, An Introduction to Fire Dynamics, John Wiley \& Sons, West Sussex, UK, 2011.

[54] Y. Fukuda, D. Kamikawa, Y. Hasemi, and K. Kagiya, "Flame characteristics of group fires," Fire Science and Technology, vol. 23, no. 2, pp. 164-169, 2004.

[55] A. A. Brown and K. P. Davis, Forest Fire: Control and Use, McGraw-Hill, New York, NY, USA, 1973.

[56] D. R. Weise and G. S. Biging, "Effects of wind velocity and slope on flame properties," Canadian Journal of Forest Research, vol. 26, no. 10, pp. 1849-1858, 1996.

[57] R. M. Nelson, B. W. Butler, and D. R. Weise, "Entrainment regimes and flame characteristics of wildland fires," International Journal of Wildland Fire, vol. 21, no. 2, pp. 127-140, 2012.

[58] P. J. W. Roberts, "Line plume and ocean outfall dispersion," Journal of the Hydraulics Division, vol. 105, no. 4, pp. 313-331, 1979.

[59] H. Rouse, W. D. Baines, and H. W. Humphreys, "Free convection over parallel sources of heat," Proceedings of the Physical Society, Section B, vol. 66, no. 5, pp. 393-399, 1953.

[60] R. M. Nelson Jr., "Power of the fire-a thermodynamic analysis," International Journal of Wildland Fire, vol. 12, no. 1, pp. 51-65, 2003.

[61] R. M. Nelson Jr., "Byram derivation of the energy criterion for forest and wildland fires," International Journal of Wildland Fire, vol. 3, no. 3, pp. 131-138, 1993.

[62] R. M. Nelson Jr and C. W. Adkins, "Flame characteristics of wind-driven surface fires," Canadian Journal of Forest Research, vol. 16, no. 6, pp. 1293-1300, 1986. 


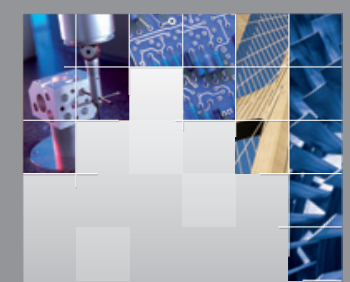

\section{Enfincering}
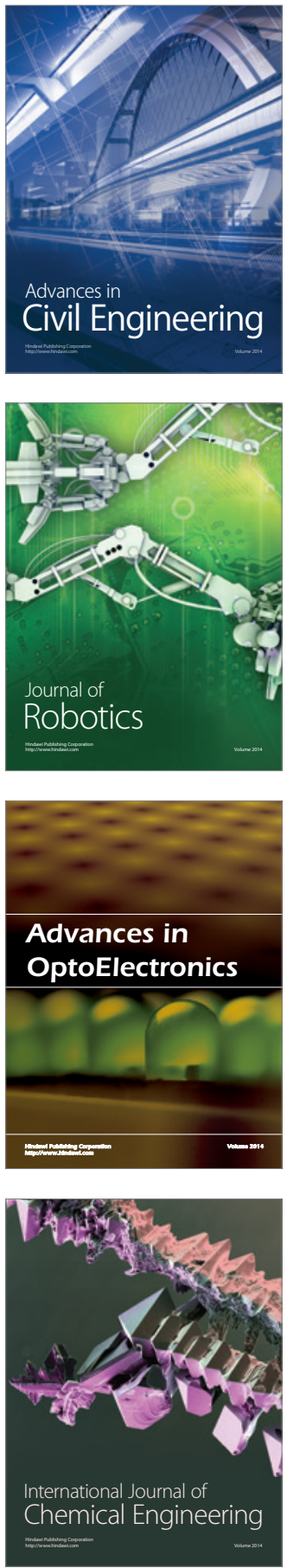

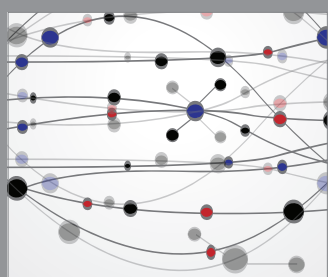

The Scientific World Journal

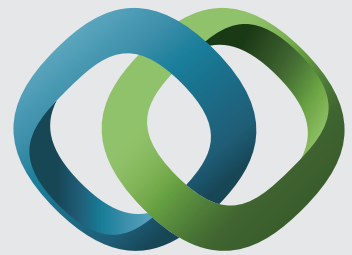

\section{Hindawi}

Submit your manuscripts at

http://www.hindawi.com
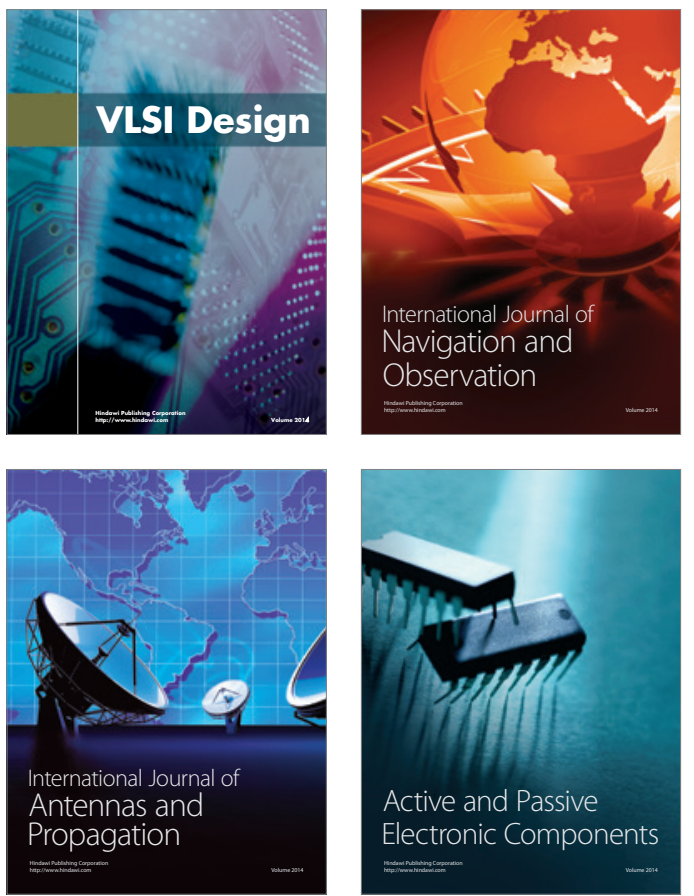
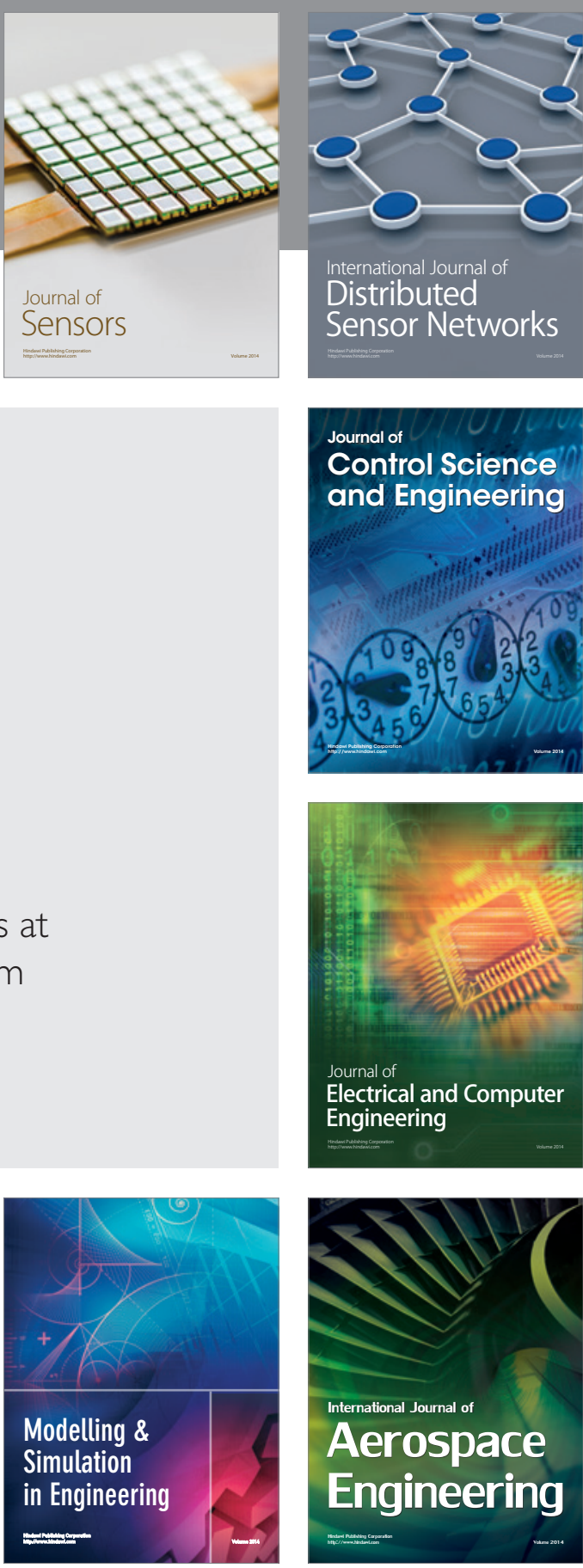

International Journal of

Distributed

Sensor Networks

Journal of

Control Science

and Engineering
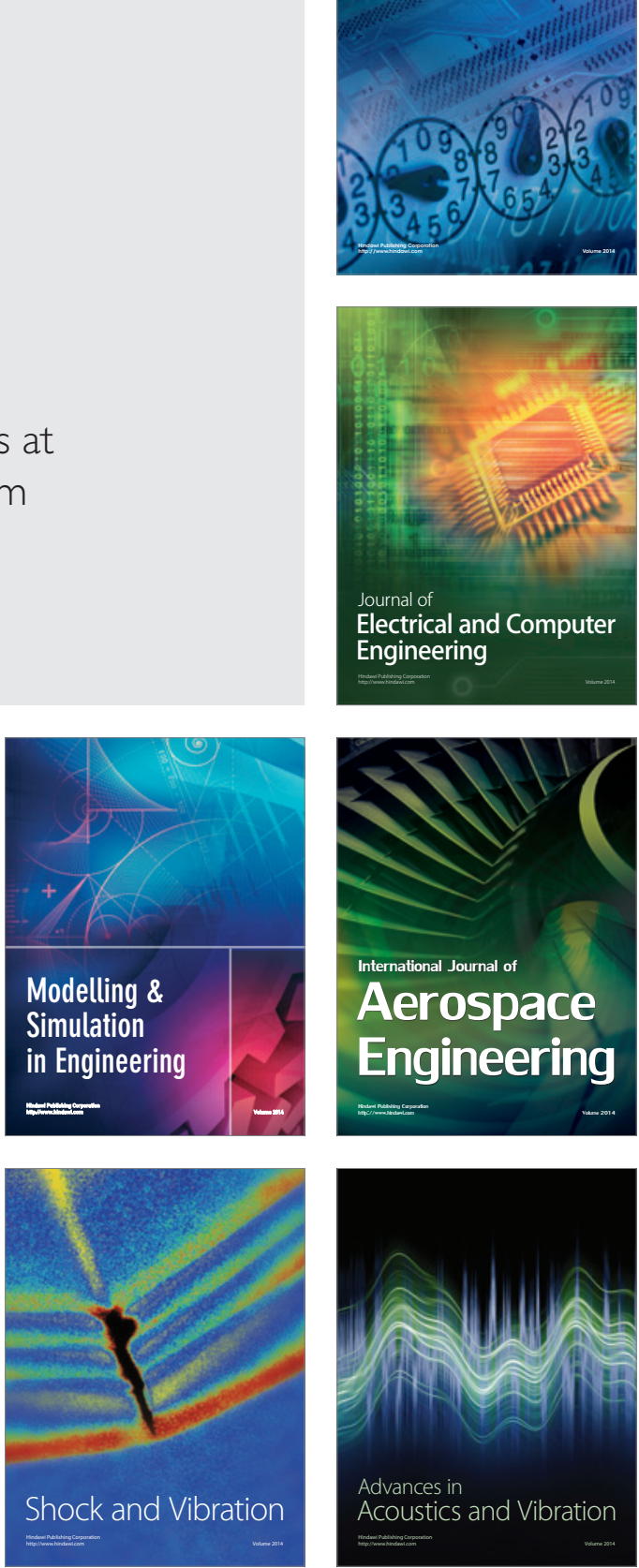